\title{
Use of Aspirin or Nonsteroidal Anti-inflammatory Drugs Increases Risk for Diverticulitis and Diverticular Bleeding
}

\section{Citation}

Strate, Lisa L., Yan L. Liu, Edward S. Huang, Edward L. Giovannucci, and Andrew T. Chan. 2011. "Use of Aspirin or Nonsteroidal Anti-Inflammatory Drugs Increases Risk for Diverticulitis and Diverticular Bleeding." Gastroenterology 140 (5): 1427-33. https://doi.org/10.1053/ j.gastro.2011.02.004.

\section{Permanent link}

http://nrs.harvard.edu/urn-3:HUL.InstRepos:41391986

\section{Terms of Use}

This article was downloaded from Harvard University's DASH repository, and is made available under the terms and conditions applicable to Other Posted Material, as set forth at http:// nrs.harvard.edu/urn-3:HUL.InstRepos:dash.current.terms-of-use\#LAA

\section{Share Your Story}

The Harvard community has made this article openly available.

Please share how this access benefits you. Submit a story.

\section{Accessibility}




\title{
Use of Aspirin or Nonsteroidal Anti-inflammatory Drugs Increases Risk for Diverticulitis and Diverticular Bleeding
}

\author{
Lisa L. Strate, M.D., M.P.H. \\ University of Washington School of Medicine, Seattle, WA and Division of Gastroenterology, \\ Department of Medicine, Harborview Medical Center, Seattle, WA
}

Yan L. Liu, M.S.

Department of Nutrition, Harvard School of Public Health, Boston, MA

Edward S. Huang, M.D.

Gastrointestinal Unit, Massachusetts General Hospital, Harvard Medical School, Boston, MA

Edward L. Giovannucci, M.D., Sc.D.

Department of Nutrition, Harvard School of Public Health, Boston, MA

Department of Epidemiology, Harvard School of Public Health, Boston, MA

Channing Laboratory, Department of Medicine, Brigham and Women's Hospital, Harvard Medical School, Boston, MA

Andrew T. Chan, M.D.,M.P.H.

Gastrointestinal Unit, Massachusetts General Hospital, Harvard Medical School, Boston, MA

Channing Laboratory, Department of Medicine, Brigham and Women's Hospital, Harvard Medical School, Boston, MA

\section{Abstract}

BACKGROUND \& AIMS-Nonsteroidal Anti-inflammatory Drugs (NSAIDs), including aspirin, have been implicated in diverticular complications. We examined the influence of aspirin and NSAID use on risk of diverticulitis and diverticular bleeding in a large prospective cohort.

METHODS-We studied 47,210 US men in the Health Professionals Follow-up Study cohort who were 40-75 years old at baseline, in 1986. We assessed use of aspirin, non-aspirin NSAIDs,

C 2011 The American Gastroenterological Association. Published by Elsevier Inc. All rights reserved

Corresponding and Reprint Author: Lisa L. Strate, MD, MPH Harborview Medical Center, 325 Ninth Avenue, Box 359773,

Seattle, WA 98104 Phone: 206-744-7058 Fax: 206-744-8698 1strate@u.washington.edu.

Author involvement: Study concept and design (Strate, Giovannucci, Chan)

Acquisition of data (Strate, Huang, Giovannucci, Chan)

Analysis and interpretation of data (Strate, Liu, Huang, Giovannucci, Chan)

Drafting of the manuscript (Strate, Chan)

Critical revision of the manuscript for important intellectual content (Strate, Liu, Huang, Giovannucci, Chan)

Statistical analysis (Liu, Huang, Chan)

Obtained funding (Giovannucci, Chan)

Study supervision (Giovannucci, Chan)

Publisher's Disclaimer: This is a PDF file of an unedited manuscript that has been accepted for publication. As a service to our customers we are providing this early version of the manuscript. The manuscript will undergo copyediting, typesetting, and review of the resulting proof before it is published in its final citable form. Please note that during the production process errors may be discovered which could affect the content, and all legal disclaimers that apply to the journal pertain.

Financial disclosure: The authors have no conflicts to disclose.

The content is solely the responsibility of the authors and does not necessarily represent the official views of the Damon Runyon Cancer Research Foundation, National Cancer Institute or the National Institutes of Health. The funding sources had no role in the design, conduct or reporting of this study. 
and other risk factors biennially. We identified men with diverticulitis or diverticular bleeding based on responses to biennial and supplemental questionnaires.

RESULTS-We documented 939 cases of diverticulitis and 256 cases of diverticular bleeding during a 22-year period of follow-up. After adjustment for risk factors, men who used aspirin regularly ( $\geq 2$ times per week) had a multivariable relative risk (RR) of 1.25 (95\% confidence interval [CI], 1.05-1.47) for diverticulitis and RR of 1.70 (95\% CI, 1.21-2.39) for diverticular bleeding, compared with non-users of aspirin and NSAIDs. Use of aspirin at intermediate doses (2-5.9 standard, $325 \mathrm{mg}$, tablets per week) and frequency (4-6 days per week) were associated with the highest risk of bleeding (multivariable $\mathrm{RR}=2.32$; 95\% CI, 1.34-4.02, and multivariable $\mathrm{RR}=3.13$; 95\% CI, 1.82-5.38, respectively). Regular users of non-aspirin NSAIDs also had an increased risk of diverticulitis (multivariable $\mathrm{RR}=1.72$; 95\% CI, 1.40-2.11) and diverticular bleeding (multivariable RR=1.74; 95\% CI, 1.15-2.64), compared with men who denied use of these medications.

CONCLUSIONS-Regular use of aspirin or NSAIDs is associated with an increased risk for diverticulitis and diverticular bleeding. Patients at risk of diverticular complications should carefully consider the potential risks and benefits of using these medications.

\section{Keywords}

Side effects; toxicity; colon medication; diverticular disease

\section{INTRODUCTION}

Nonsteroidal Anti-inflammatory Drugs (NSAIDs), including aspirin, are a well-known cause of upper gastrointestinal tract complications. These medications are also implicated in lower gastrointestinal injury. $1^{-3}$ In randomized trials of patients with rheumatoid or osteoarthritis, $30-50 \%$ of all serious gastrointestinal events associated with NSAIDs were localized to the lower gastrointestinal tract, $4^{-} 6$ with diverticulitis and diverticular bleeding as the most common etiologies.5, 6 Although a number of case-control studies have demonstrated a significantly higher prevalence of NSAID use among cases with complications of diverticular disease (diverticulitis and bleeding) compared to controls, risk estimates vary widely, with odds ratios ranging from 1.8 to $16.7^{-} 12$ In addition to the inherent biases in selection of controls and ascertainment of medication exposure associated with the casecontrol study design, these analyses also had limited data regarding medication type (NSAID versus aspirin), dose, timing and duration of use.

Thus, to address these limitations, we prospectively examined the influence of aspirin and NSAIDs on risk of diverticular complications in a large cohort of men enrolled in the Health Professionals Follow-up Study which provided long-term, detailed, and updated information on aspirin and NSAID use. In an earlier study of this cohort, we found that regular NSAID use, but not aspirin use, was positively associated with symptomatic diverticular disease; 13 however, that analysis was limited by the number of overall cases $(n=310)$, short follow-up (4 years), the inability to evaluate medication dose and frequency or differentiate diverticulitis or diverticular bleeding from gastrointestinal symptoms that arose in the setting of diverticulosis. In the present study, we offer results that include detailed data on aspirin and NSAID dose and frequency, encompassing 22 years of follow-up with 939 cases of diverticulitis and 256 cases of diverticular bleeding. 


\section{MATERIALS and METHODS}

\section{Study Population}

The Health Professionals Follow-up Study is a prospective cohort of 51,529 male dentists, veterinarians, pharmacists, optometrists, osteopathic physicians and podiatrists who were aged 40-75 years at baseline in 1986 and returned a detailed medical and dietary questionnaire. Medical information has been updated biennially and dietary information every 4 years via self-administered questionnaires.

\section{Assessment of Diverticulitis and Diverticular Bleeding}

The primary study endpoints were diverticulitis and diverticular bleeding. Beginning in 1990, men reporting newly diagnosed diverticulosis or diverticulitis on the biennial main study questionnaire were sent supplementary questionnaires to assess the date of diagnosis, procedures performed to confirm the diagnosis, symptoms or tests leading to the detection of diverticular disease, and treatment received. We defined cases of complicated diverticulitis as a report of a fistula, abscess, perforation or obstruction. We defined cases of uncomplicated diverticulitis as reports of abdominal pain attributed to diverticular disease requiring antibiotics, hospitalization, or surgery; pain categorized as severe or acute; or abdominal pain presenting with fever, requiring medication, or evaluated with computed tomography. Diverticular bleeding was defined as rectal bleeding attributed to diverticulosis that required hospitalization, blood transfusions, intravenous fluids, surgery, angiography, tagged red blood cell scanning or endoscopic hemostasis. We have previously used these case definitions and have reported our methods for validation in detail.14-16

In addition, beginning in 2006, we updated the supplemental questionnaire to include a checklist of diverticular complications with definitions (diverticular bleeding; uncomplicated diverticulitis;diverticular abscess, obstruction, perforation and fistula) in addition to questions regarding diagnosis and treatment. . In 2006, among all participants, we also inquired about gastrointestinal bleeding requiring hospitalization or blood transfusion, the location of the bleeding and the date of onset. In a review of 239 cases, selfreported date of diagnosis correlated with the medical record (correlation coefficient $0.87, \mathrm{p}$ $<0.001$ ), and self-reported location of bleeding (upper versus lower) was correct in $93 \%$. Therefore, patients who reported diverticular disease and gastrointestinal bleeding from the colon requiring hospitalization or blood transfusion in corresponding study periods were classified as having diverticular bleeding, and cases in addition to those documented via the supplemental questionnaire were included.

\section{Assessment of Medication Use}

We have previously detailed our assessment of aspirin and NSAID use (26). Briefly, since 1986, the biennial study questionnaire assessed regular use (defined as 2 or more times per week) of aspirin (e.g. Anacin, Bufferin, Alka-Seltzer) and other anti-inflammatory drugs (e.g. Motrin, Indocin, Naprosyn, Dolobid). In 1992, additional questions were added to assess the average number of aspirin tablets used per week and the frequency of aspirin use. Due to secular trends in the use of baby or low-dose aspirin, beginning in 1994, participants were instructed to convert baby aspirin to standard tablets ( 4 baby aspirin $=1$ tablet). Indications for aspirin use were assessed on a 1993 supplementary questionnaire sent to 221 men who reported aspirin use since 1986. Indications for aspirin use included cardiovascular disease (25.4\%), to decrease the risk of cardiovascular disease (58.4\%), headaches (25.4\%), joint or musculoskeletal pain (33\%) and other (7\%).17 No participant reported taking aspirin for the relief of abdominal pain. 


\section{Assessment of Other Potential Risk Factors}

We also assessed dietary fiber, fat, red meat, corn, popcorn and nut intake, physical activity and obesity as potential confounders.14-16, $18^{-} 22$ Nutritional information was assessed every 4 years using a food frequency questionnaire. Physical activity was assessed on biennial questionnaires, and expressed in metabolic equivalents (MET) hours per week. Body mass index $\left(\mathrm{kg} / \mathrm{m}^{2}\right)$ was calculated from self-reported body weight that was updated biennially, and height which was reported at baseline in 1986. The validity and reproducibility of the dietary questionnaires, body measurements and physical activity assessment have been demonstrated previously. $23^{-} 25$

\section{Statistical Analysis}

We excluded from the analysis men who reported a diagnosis of diverticulosis, diverticulitis or diverticular bleeding, cancer (except non-melanoma skin cancer), or inflammatory bowel disease on the baseline questionnaire. In addition, we excluded men who did not return the baseline food frequency questionnaire or provided implausible dietary data (men with average daily intakes outside the range of $800-4,300 \mathrm{kcal}$ ). The remaining baseline population included 47,210 men. Men contributed person-time from the date of return of the baseline questionnaire in 1986 to the date of the first diagnosis of diverticular complications, the date of death, or December 31,2008, whichever came first. Men who reported a new diagnosis of gastrointestinal cancer, diverticulosis, diverticulitis, diverticular bleeding, or inflammatory bowel disease were censored at the date of diagnosis.

We examined the association between regular use of aspirin and NSAIDs and the incidence of diverticulitis and diverticular bleeding using simple updating (the medication use reported on the questionnaire immediately preceding the follow-up interval of interest). Consistent with prior analyses, regular use was defined as 2 or more times per week, and non-regular use as less than 2 times per week.17, 26 For this analysis, regular users of aspirin only, NSAIDs only, and both aspirin and NSAIDs were compared separately to non-users of both aspirin and NSAIDs. Frequency of aspirin use was also evaluated according to the average number of days aspirin was used per week in categories. In addition, we assessed the relationship between aspirin dose and the risk of diverticular complications. Dose was estimated and categorized according to the number of standard dose (325mg) tablets used per week. We evaluated cumulative updated dose to account for variation in dose over the study period using time-varying covariates. In this analysis, each participant contributed person-time according to data they provided on each biennial questionnaire. Lastly, we examined the risk of diverticular complications according to the duration of aspirin and NSAID use. Duration was calculated in years of regular use beginning in 1986 with updating every 2 years and accounting for interruptions in usage.

We divided the number of new cases of diverticulitis and diverticular bleeding by the number of person-years in each use category to calculate incidence rates. Hazard ratios (HR) and $95 \%$ confidence intervals (CI) were calculated for each endpoint using Cox proportional hazards models. Men in each category of use were compared to men in the reference category (non-regular users).27 Age-adjusted models were stratified by age in one-year intervals and study period in two-year intervals. Multivariable models adjusted for age and study period as well as body mass index (6 categories), dietary intake (quintiles) of fat, fiber, red meat, nut, corn and popcorn consumption, total caloric intake, and physical activity (quintiles). We utilized the most recent information available for each covariate. We excluded NSAID users from the analyses of aspirin use, and aspirin users from the analyses of NSAID use to better isolate the effect of each drug individually. We assessed statistical interaction of aspirin and NSAID use by including cross-product terms in our models and assessing their significance using the Wald test. 
All analyses were performed using SAS software, version 9.1.3 (SAS Institute Inc., Cary, North Carolina). Tests for linear trend were performed by treating the median value of each of the measurement categories as a continuous variable.28 All tests were two-sided and a p value of less than 0.05 was considered statistically significant. Return of the selfadministered study questionnaire was regarded as informed consent. The institutional review boards of the Harvard School of Public Health approved the study protocol.

\section{RESULTS}

During 859,164 person years of follow-up, we documented 939 incident cases of diverticulitis, and 256 incident cases of diverticular bleeding. Baseline characteristics of the cohort are summarized in Table 1 according to regular use of aspirin and NSAIDs and standardized for age. Approximately $29 \%$ of participants reported regular aspirin use (2 or more times per week) and 5\% reported regular NSAID use. On average, regular users of aspirin were more likely to have a history of coronary heart disease than non-users, and users of aspirin and NSAIDs were more likely to have osteoarthritis and to consume more alcohol than non-users.

After controlling for other potential risk factors for diverticular complications, we observed a significantly higher risk of diverticulitis among regular users of NSAIDs (multivariable HR 1.72; 95\% CI, 1.40-2.11), and to a lesser degree among regular users of aspirin (multivariable HR 1.25; 95\% CI, 1.05-1.47) when compared with men who denied use of either drug (Table 2). In analyses according to subtypes of diverticulitis, we observed that regular NSAID use appeared to be more strongly associated with risk of complicated diverticulitis (multivariable HR 2.55; 95\% CI, 1.32-4.95) than uncomplicated diverticulitis (multivariable HR 1.65; 95\% CI, 1.32-2.05) compared to non-use of either NSAIDs or aspirin. For both subtypes, we found comparable risk estimates for regular aspirin use, with a multivariable HR of 1.13 (95\% CI, 0.61-2.10) for complicated diverticulitis and 1.24 (95\% CI, 1.04-1.47) for uncomplicated diverticulitis.

For diverticular bleeding, the associations of regular use of NSAIDs and aspirin were similar (multivariable HR 1.74; 95\% CI, 1.15-2.64 and multivariable HR 1.70; 95\% CI, 1.21-2.39, respectively). Combined use of aspirin and NSAIDs was associated with a multivariable HR for diverticulitis of 1.65 (95\% CI, 1.36-2.01) and for bleeding of 2.02 (95\% CI, 1.38-2.96). A formal test of whether the concurrent use of aspirin and NSAIDs was associated with greater risk than use of each drug alone was not statistically significant for diverticulitis $(\mathrm{p}=0.06)$ or for bleeding $(\mathrm{p}=0.145)$..

The association between aspirin use and diverticular complications did not display a linear dose-relationship in the multivariable analyses excluding NSAID users ( $\mathrm{p}=0.28$ for trend for diverticulitis and $\mathrm{p}=0.10$ for trend for diverticular bleeding) (Table 3). However, we observed that men who took intermediate doses of aspirin (2-5.9 standard $(325 \mathrm{mg})$ tablets per week) had the highest risk of diverticular bleeding (multivariable HR 2.32; 95\% CI, 1.34-4.02) when compared to men who reported no aspirin use.

To better assess the effect of consistency of use on the risk of diverticular complications, we also examined frequency of regular aspirin use in non-NSAID users (Table 4). Compared to non-regular users, men who used aspirin daily had a significantly higher risk of diverticulitis (multivariable HR 1.46; 95\% CI, $1.13-1.88, \mathrm{p}=0.002$ for trend). Similar to the findings for aspirin dose, we found that moderately frequent use of aspirin was strongly associated with the risk of diverticular bleeding. Men who reported aspirin use 4-6 days per week had a multivariable HR of 3.13 (95\% CI, 1.82-5.38) when compared to men who denied aspirin use. 
In addition, we found that increasing duration of regular aspirin and NSAID use was associated with greater risk of diverticular complications among non-users of NSAIDs and aspirin, respectively. Ten years or more of aspirin use was associated with a multivariable HR of 1.51 (95\% CI, 1.13-2.03, p=0.01 for trend) for diverticulitis, and 2.53 (95\% CI, 1.43$4.46, \mathrm{p}=0.003$ for trend) for bleeding compared to non-regular use. Likewise, after 10 years of NSAID use the HR of diverticulitis was 1.80 (95\% CI, 1.30-2.51, p<0.001 for trend), and of diverticular bleeding was 2.17 (95\% CI, $1.23-2.85$, $\mathrm{p}=0.006$ for trend).

To address the possibility of confounding by comorbid illness, we additionally adjusted our analyses for cardiovascular disease and osteoarthritis, the two most common indications for aspirin use in this cohort. In this analysis, the relationships between aspirin and NSAID use and diverticulitis remained largely unchanged (multivariable HR 1.20; 95\% CI, 1.01-1.42 for aspirin and multivariable 1.64; 95\% CI, 1.33-2.02 for NSAIDs). For diverticular bleeding, the association with aspirin use was not materially altered (multivariable HR 1.66; 95\% CI, 1.18-2.33), but the association with NSAIDs was somewhat attenuated (multivariable HR 1.42; 95\% CI, 0.92-2.18).

\section{DISCUSSION}

In this large, prospective study of men, we observed that regular use of aspirin or NSAIDs was associated with an increased risk of diverticulitis and diverticular bleeding. The magnitude of the increased risk of bleeding was similar for regular aspirin and NSAID users. The highest risk of diverticular bleeding was observed in men who used aspirin with moderately high frequency (4-6 days per week) and in moderately high doses (2 to5.9 standard (325mg) tablets per week). For diverticulitis, the risk appeared somewhat greater for regular NSAID users than for regular aspirin users, and the risk increased with frequency of aspirin use but not with higher doses.

Several previous case-control studies and one prospective cohort study have observed similar associations between aspirin and/or NSAID use and diverticular complications. $7^{-} 13$ Our study expands on these findings in several notable ways. First, we distinguished diverticulitis from diverticular bleeding and studied a spectrum of complications. In contrast, aside from one small study of diverticular bleeding, 12 prior studies have focused on perforated diverticulitis, $8^{-} 10$ a severe manifestation, or combined diverticulitis and diverticular bleeding. $7,11,13$ This differentiation is important because diverticulitis and diverticular bleeding likely have distinct biologic mechanisms, and it is not known whether aspirin or NSAIDs serve to initiate or promulgate complications. Second, we were able to examine separately the effects of aspirin and NSAID use, whereas most prior studies utilized a combined exposure measure.7, $8,10,11$ Third, we collected detailed data on aspirin use during 22 years of prospective follow-up, which enabled us to disentangle the specific effects of dose, frequency, duration and timing of medication use in relation to diverticular complications. Lastly, we were able to adjust for many important known potential confounders of diverticular complications including diet, body mass index and physical activity.

There are several potential mechanisms by which aspirin and NSAIDs may promote diverticular complications. NSAIDs, including aspirin, are thought to damage the colon via direct topical injury and/or impaired prostaglandin synthesis which compromise mucosal integrity, increase permeability, and enable the influx of bacteria and other toxins.29 Diverticulitis is defined by the presence of micro- or macro-perforation leading to abscess formation, and is believed to be the result of an impaired mucosal barrier and increased intracolonic pressure.30 Diverticular bleeding occurs when a nutrient artery ruptures into the colon lumen, and commonly involves local mucosal ulceration in the absence of 
inflammation.31, 32 In addition, NSAIDs, including aspirin, likely promote blood loss from existing lesions via inhibition of platelet aggregation.

Our results indicate that NSAID use is more strongly associated with diverticulitis than aspirin use. In fact, the hazard ratio of combined NSAID and aspirin use was similar to the risk of NSAID use alone. This result is supported by several other studies in which aspirin and NSAID use were evaluated independently. In an earlier analysis of the Health Professionals Follow-up cohort, NSAID use was significantly associated with symptomatic diverticular disease whereas aspirin use was not.13 In a case control study, Morris et al. found that NSAID, but not aspirin use, was associated with perforated diverticulitis. $9 \mathrm{We}$ also found a stronger association between NSAIDs and complicated diverticulitis. Although the association with NSAIDs remained significant when excluding individuals with complicated disease, the study questionnaires did not explicitly denote complications prior to 2006, and it is possible that the observed associations are largely due to complicated diverticulitis. The greater effect of NSAIDs versus aspirin in diverticulitis may be due in part to the fact that low-dose aspirin is primarily absorbed in the stomach and duodenum, limiting topical injury to the colon. $29 \mathrm{We}$ found that men in the moderately high dose and frequency categories of aspirin use were at a somewhat higher risk of diverticular bleeding than men in the highest categories. The anti-platelet effects of aspirin may account for these findings. At low and moderate doses of aspirin the predominant effect is on the cyclooxygenase (COX)- 1 isoenzyme leading to thromboxane A2 mediated platelet inhibition. 33 However, at higher doses aspirin may preferentially inhibit the COX-2 isoenzyme which promotes thrombosis and vasoconstriction rather than bleeding.33 Indeed, several studies, suggest that higher aspirin doses are associated with somewhat greater risk of thrombotic cardiovascular events. $34^{-} 36$

Our study has several limitations. Diverticular complications and medication use were selfreported. However, study participants were well-educated health care professionals who likely accurately report their diagnoses and medication use. Moreover, we confirmed selfreported outcomes via chart review in a subset of individuals and self-reported aspirin and NSAID use in this cohort have been previously associated with several disease outcomes which have been separately validated.16, 26 Any misclassification bias is likely to be nondifferential, resulting in an underestimate of any true association between NSAID and aspirin use and diverticular complications. Given the observational nature of our study, we cannot exclude the possibility of residual confounding. Nonetheless, controlling for purported risk factors for diverticular complications including diet and lifestyle did not appreciably alter our results. In addition, our results are consistent with previous investigations and have clear biologic plausibility. We were unable to examine the impact of NSAID dose and frequency or COX-2 selective inhibitor use due to the limited follow-up (NSAID dose and duration were assessed since 2000 and COX-2 selective use since 2004). Finally, our study cohort consisted of male health professionals, which may limit the generalizability of our results to other populations. However, we would not expect the association of aspirin with bleeding to differ by occupation..

In conclusion, we observed significantly elevated risks of diverticulitis and diverticular bleeding among users of aspirin and NSAIDs. These findings have important clinical and public health implications given the prevalence of diverticular disease and NSAID use particularly in the elderly.37, 38 Analgesia should be selected carefully in individuals with diverticulosis, especially those with prior complications. Future studies are needed to better identify individuals at risk of diverticular complications, and to develop strategies to mitigate the lower gastrointestinal toxicity of NSAIDs. 


\section{Acknowledgments}

Grant support: The project described was funded by a grant from the National Institutes of Health (CA55075). Dr. Chan is a Damon Runyon Cancer Research Foundation Clinical Investigator. Dr. Huang is supported by an American Gastroenterological Association Fellow to Faculty Transition Award.

\section{Abbreviations}

(NSAIDs) Nonsteroidal anti-inflammatory drugs

(BMI) Body Mass Index

(HR) Hazard Ratio

(CI) Confidence Interval

\section{REFERENCES}

1. Lanas A, Sekar MC, Hirschowitz BI. Objective evidence of aspirin use in both ulcer and nonulcer upper and lower gastrointestinal bleeding. Gastroenterology. 1992; 103:862-9. [PubMed: 1499936]

2. Lanas A, Serrano P, Bajador E, Esteva F, Benito R, Sainz R. Evidence of aspirin use in both upper and lower gastrointestinal perforation. Gastroenterology. 1997; 112:683-9. [PubMed: 9041228]

3. Langman MJ, Morgan L, Worrall A. Use of anti-inflammatory drugs by patients admitted with small or large bowel perforations and haemorrhage. Br Med J (Clin Res Ed). 1985; 290:347-9.

4. Chan FK, Hung LC, Suen BY, Wu JC, Lee KC, Leung VK, Hui AJ, To KF, Leung WK, Wong VW, Chung SC, Sung JJ. Celecoxib versus diclofenac and omeprazole in reducing the risk of recurrent ulcer bleeding in patients with arthritis. N Engl J Med. 2002; 347:2104-10. [PubMed: 12501222]

5. Laine L, Connors LG, Reicin A, Hawkey CJ, Burgos-Vargas R, Schnitzer TJ, Yu Q, Bombardier C. Serious lower gastrointestinal clinical events with nonselective NSAID or coxib use. Gastroenterology. 2003; 124:288-92. [PubMed: 12557133]

6. Laine L, Curtis SP, Langman M, Jensen DM, Cryer B, Kaur A, Cannon CP. Lower gastrointestinal events in a double-blind trial of the cyclo-oxygenase-2 selective inhibitor etoricoxib and the traditional nonsteroidal anti-inflammatory drug diclofenac. Gastroenterology. 2008; 135:1517-25. [PubMed: 18823986]

7. Campbell K, Steele RJ. Non-steroidal anti-inflammatory drugs and complicated diverticular disease: a case-control study. Br J Surg. 1991; 78:190-1. [PubMed: 2015469]

8. Goh H, Bourne R. Non-steroidal anti-inflammatory drugs and perforated diverticular disease: a case-control study. Ann R Coll Surg Engl. 2002; 84:93-6. [PubMed: 11995772]

9. Morris CR, Harvey IM, Stebbings WS, Speakman CT, Kennedy HJ, Hart AR. Anti-inflammatory drugs, analgesics and the risk of perforated colonic diverticular disease. Br J Surg. 2003; 90:126772. [PubMed: 14515298]

10. Mpofu S, Mpofu CM, Hutchinson D, Maier AE, Dodd SR, Moots RJ. Steroids, nonsteroidal antiinflammatory drugs, and sigmoid diverticular abscess perforation in rheumatic conditions. Ann Rheum Dis. 2004; 63:588-90. [PubMed: 15082493]

11. Wilson RG, Smith AN, Macintyre IM. Complications of diverticular disease and nonsteroidal antiinflammatory drugs: a prospective study. Br J Surg. 1990; 77:1103-4. [PubMed: 2121310]

12. Yamada A, Sugimoto T, Kondo S, Ohta M, Watabe H, Maeda S, Togo G, Yamaji Y, Ogura K, Okamoto M, Yoshida H, Kawabe T, Kawase T, Omata M. Assessment of the risk factors for colonic diverticular hemorrhage. Dis Colon Rectum. 2008; 51:116-20. [PubMed: 18085336]

13. Aldoori WH, Giovannucci EL, Rimm EB, Wing AL, Willett WC. Use of acetaminophen and nonsteroidal anti-inflammatory drugs: a prospective study and the risk of symptomatic diverticular disease in men. Arch Fam Med. 1998; 7:255-60. [PubMed: 9596460]

14. Strate LL, Liu YL, Aldoori WH, Giovannucci EL. Physical activity decreases diverticular complications. Am J Gastroenterol. 2009; 104:1221-30. [PubMed: 19367267] 
15. Strate LL, Liu YL, Aldoori WH, Syngal S, Giovannucci EL. Obesity increases the risks of diverticulitis and diverticular bleeding. Gastroenterology. 2009; 136:115-122. e1. [PubMed: $18996378]$

16. Strate LL, Liu YL, Syngal S, Aldoori WH, Giovannucci EL. Nut, corn, and popcorn consumption and the incidence of diverticular disease. JAMA. 2008; 300:907-14. [PubMed: 18728264]

17. Giovannucci E, Rimm EB, Stampfer MJ, Colditz GA, Ascherio A, Willett WC. Aspirin use and the risk for colorectal cancer and adenoma in male health professionals. Ann Intern Med. 1994; 121:241-6. [PubMed: 8037405]

18. Aldoori WH, Giovannucci EL, Rimm EB, Wing AL, Trichopoulos DV, Willett WC. A prospective study of diet and the risk of symptomatic diverticular disease in men. Am J Clin Nutr. 1994; 60:757-64. [PubMed: 7942584]

19. Aldoori WH, Giovannucci EL, Rockett HR, Sampson L, Rimm EB, Willett WC. A prospective study of dietary fiber types and symptomatic diverticular disease in men. J Nutr. 1998; 128:714-9. [PubMed: 9521633]

20. Dobbins C, Defontgalland D, Duthie G, Wattchow DA. The relationship of obesity to the complications of diverticular disease. Colorectal Dis. 2006; 8:37-40. [PubMed: 16519636]

21. Manousos O, Day NE, Tzonou A, Papadimitriou C, Kapetanakis A, PolychronopoulouTrichopoulou A, Trichopoulos D. Diet and other factors in the aetiology of diverticulosis: an epidemiological study in Greece. Gut. 1985; 26:544-9. [PubMed: 3924745]

22. Rosemar A, Angeras U, Rosengren A. Body Mass Index and Diverticular Disease: A 28-Year Follow-Up Study in Men. Dis Colon Rectum. 2007

23. Chasan-Taber S, Rimm EB, Stampfer MJ, Spiegelman D, Colditz GA, Giovannucci E, Ascherio A, Willett WC. Reproducibility and validity of a self-administered physical activity questionnaire for male health professionals. Epidemiology. 1996; 7:81-6. [PubMed: 8664406]

24. Rimm EB, Giovannucci EL, Stampfer MJ, Colditz GA, Litin LB, Willett WC. Reproducibility and validity of an expanded self-administered semiquantitative food frequency questionnaire among male health professionals. Am J Epidemiol. 1992; 135:1114-26. discussion 1127-36. [PubMed: 1632423]

25. Rimm EB, Stampfer MJ, Colditz GA, Chute CG, Litin LB, Willett WC. Validity of self-reported waist and hip circumferences in men and women. Epidemiology. 1990; 1:466-73. [PubMed: 2090285]

26. Chan AT, Giovannucci EL, Meyerhardt JA, Schernhammer ES, Wu K, Fuchs CS. Aspirin dose and duration of use and risk of colorectal cancer in men. Gastroenterology. 2008; 134:21-8. [PubMed: 18005960]

27. Cox DR. Regression models and life tables. J R Stat Soc (B). 1972; 34:187-220.

28. Ascherio A, Rimm EB, Hernan MA, Giovannucci E, Kawachi I, Stampfer MJ, Willett WC. Relation of consumption of vitamin E, vitamin C, and carotenoids to risk for stroke among men in the United States. Ann Intern Med. 1999; 130:963-70. [PubMed: 10383366]

29. Lanas A, Sopena F. Nonsteroidal anti-inflammatory drugs and lower gastrointestinal complications. Gastroenterol Clin North Am. 2009; 38:333-52. [PubMed: 19446262]

30. Morris CR, Harvey IM, Stebbings WS, Speakman CT, Kennedy HJ, Hart AR. Epidemiology of perforated colonic diverticular disease. Postgrad Med J. 2002; 78:654-8. [PubMed: 12496319]

31. Foutch PG. Diverticular bleeding: are nonsteroidal anti-inflammatory drugs risk factors for hemorrhage and can colonoscopy predict outcome for patients? Am J Gastroenterol. 1995; 90:1779-84. [PubMed: 7572894]

32. Meyers MA, Alonso DR, Baer JW. Pathogenesis of massively bleeding colonic diverticulosis: new observations. AJR Am J Roentgenol. 1976; 127:901-8. [PubMed: 1087123]

33. Patrono C, Garcia Rodriguez LA, Landolfi R, Baigent C. Low-dose aspirin for the prevention of atherothrombosis. N Engl J Med. 2005; 353:2373-83. [PubMed: 16319386]

34. Collaborative meta-analysis of randomised trials of antiplatelet therapy for prevention of death, myocardial infarction, and stroke in high risk patients. BMJ. 2002; 324:71-86. [PubMed: 11786451]

35. Taylor DW, Barnett HJ, Haynes RB, Ferguson GG, Sackett DL, Thorpe KE, Simard D, Silver FL, Hachinski V, Clagett GP, Barnes R, Spence JD. Low-dose and high-dose acetylsalicylic acid for 
patients undergoing carotid endarterectomy: a randomised controlled trial. ASA and Carotid Endarterectomy (ACE) Trial Collaborators. Lancet. 1999; 353:2179-84. [PubMed: 10392981]

36. Chan AT, Manson JE, Albert CM, Chae CU, Rexrode KM, Curhan GC, Rimm EB, Willett WC, Fuchs CS. Nonsteroidal antiinflammatory drugs, acetaminophen, and the risk of cardiovascular events. Circulation. 2006; 113:1578-87. [PubMed: 16534006]

37. Shaheen NJ, Hansen RA, Morgan DR, Gangarosa LM, Ringel Y, Thiny MT, Russo MW, Sandler RS. The burden of gastrointestinal and liver diseases, 2006. Am J Gastroenterol. 2006; 101:212838. [PubMed: 16848807]

38. Talley NJ, Evans JM, Fleming KC, Harmsen WS, Zinsmeister AR, Melton LJ 3rd. Nonsteroidal antiinflammatory drugs and dyspepsia in the elderly. Dig Dis Sci. 1995; 40:1345-50. [PubMed: 7781458] 
Table 1

Baseline Characteristics of the Study Cohort in 1986 According to Regular Use of Aspirin and NSAID

\begin{tabular}{|c|c|c|c|c|}
\hline & \multicolumn{2}{|c|}{ Aspirin } & \multicolumn{2}{|c|}{ NSAIDs } \\
\hline & Non-regular users $n=33336$ & Regular users n=13874 & Non-regular users $n=\mathbf{4 4 6 3 3}$ & Regular users $\mathbf{n}=\mathbf{2 5 7 7}$ \\
\hline Age, mean (SD), y & $53(9.7)$ & $56(9.7)$ & $54(9.7)$ & $55(9.9)$ \\
\hline $\begin{array}{l}\text { Body mass index, mean } \\
\text { (SD), } \mathrm{kg} / \mathrm{m}^{2}\end{array}$ & $24.9(5.0)$ & $25.1(5.2)$ & $24.9(5.0)$ & $25.5(5.6)$ \\
\hline $\begin{array}{l}\text { Physical activity, mean } \\
\text { (SD), MET, h/wk }\end{array}$ & $21(29.5)$ & $21(28.8)$ & $21(29.3)$ & $21(29.5)$ \\
\hline $\begin{array}{l}\text { Coronary heart disease } \\
(\%)\end{array}$ & 4 & 12 & 6 & 6 \\
\hline Osteoarthritis (\%)x & 7 & 11 & 7 & 36 \\
\hline Current smoking (\%) & 9 & 10 & 10 & 10 \\
\hline \multicolumn{5}{|l|}{ Dietary intake, mean (SD) } \\
\hline Calories (kcal/day) & 1973 (617) & $2018(623)$ & 1984 (619) & $2017(623)$ \\
\hline Fiber (g/day) & $21(7.0)$ & $21(7.0)$ & $21(7.1)$ & $21(6.7)$ \\
\hline Fat (g/day) & $72(14.0)$ & $71(14.1)$ & $71(14.1)$ & $72(13.7)$ \\
\hline Red meat (servings/day) & $4.3(3.2)$ & $4.3(3.1)$ & $4.3(3.2)$ & $4.5(3.2)$ \\
\hline Alcohol (g/day), mean & $11(15.0)$ & $13(16.3)$ & $11(15.4)$ & $13(16.7)$ \\
\hline Current NSAID use (\%) & 5 & 7 & - & - \\
\hline Current Aspirin use (\%) & - & - & 29 & 39 \\
\hline
\end{tabular}

NOTE. All variables except for age are age-standardized.

NSAID, nonsteroidal anti-inflammatory drug; MET, metabolic equivalent

Regular use was defined as at least 2 times per week. Non-regular use was defined as less than 2 times per week. 
Table 2

Aspirin and NSAID Use and the Risk of Diverticulitis and Diverticular Bleeding ${ }^{a}$

\begin{tabular}{lcccc}
\hline & $\begin{array}{c}\text { Non-users of } \\
\text { Aspirin and } \\
\text { NSAIDs }\end{array}$ & $\begin{array}{c}\text { Regular Use of Aspirin } \\
\text { only }\end{array}$ & $\begin{array}{c}\text { Regular Use of NSAIDs } \\
\text { only }\end{array}$ & $\begin{array}{c}\text { Regular Use of Aspirin } \\
\text { and NSAIDs }\end{array}$ \\
$\begin{array}{l}\text { Person Years } \\
\text { Diverticulitis }\end{array}$ & 367,223 & 273,233 & 96,726 & 120,609 \\
$\quad$ Incident cases & 288 & 313 & 148 & 190 \\
$\quad$ Age-adjusted HR $(95 \% \mathrm{CI})^{b}$ & 1.0 & $1.32(1.12-1.55)$ & $1.87(1.52-2.29)$ & $1.85(1.53-2.42)$ \\
$\quad$ Multivariate HR $(95 \% \mathrm{CI})^{c}$ & 1.0 & $1.25(1.05-1.47)$ & $1.72(1.40-2.11)$ & $1.65(1.36-2.01)$ \\
Diverticular Bleeding & & & & 65 \\
$\quad$ Incident cases & 58 & 93 & 40 & $2.45(1.69-3.53)$ \\
Age-adjusted HR $(95 \% \mathrm{CI})^{b}$ & 1.0 & $1.90(1.36-2.65)$ & $1.92(1.27-2.91)$ & $2.02(1.38-2.96)$ \\
$\quad$ Multivariate HR $(95 \% \mathrm{CI})^{c}$ & 1.0 & $1.70(1.21-2.39)$ & $1.74(1.15-2.64)$ & \\
\hline
\end{tabular}

${ }^{a}$ Regular use was defined as at least 2 times per week. Non-regular use was defined as less than 2 times per week.

${ }^{b}$ Age-adjusted HRs adjusted for age (in years) and study period in 2-year intervals

${ }^{c}$ Multivariate HR adjusted for age, study period, body mass index, dietary fat, fiber, red meat, nut, corn and total caloric intake, and physical activity 


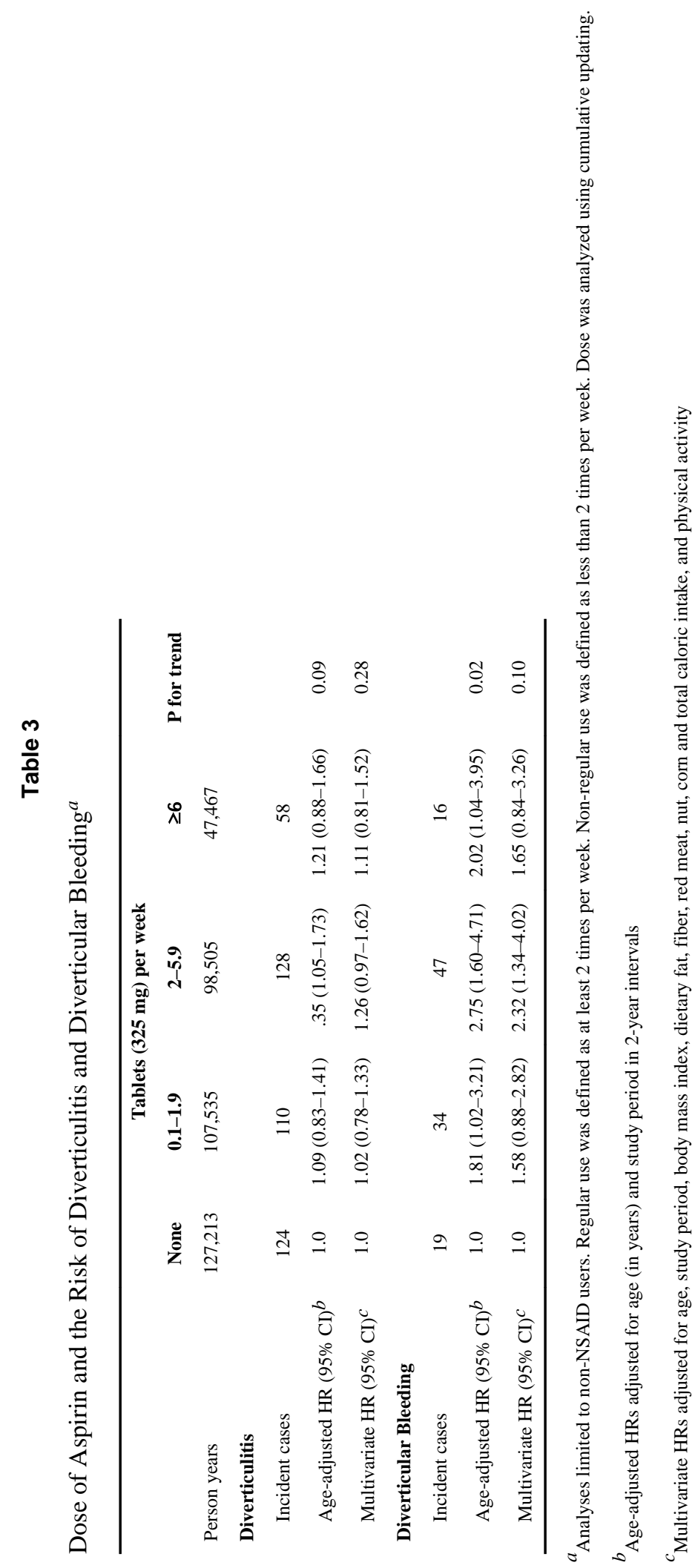

Gastroenterology. Author manuscript; available in PMC 2012 May 1. 
